\section{Short footshock-electroconvulsive shock intervals and retrograde amnesia in mice}

\author{
GEORGE S. GROSSER, HECTOR E. PERCY, and LINDA E. PIERCE \\ American International College, Springfield, Mass. 01109
}

Electroconvulsive shock (ECS) was administered to mice $0,1,2,4$, and 8 sec following a step-through passive avoidance trial. On retest $24 \mathrm{~h}$ later, the minimum test trial step-through latencies (STLs) were shown by groups given ECS $2 \mathrm{sec}$ and $4 \mathrm{sec}$ after a 1 -sec footshock (FS); however, the Ss in the 2-sec group showed very little variation in STLs. Since the 2-sec and 4-sec groups showed test latencies lower than their training STLs, a "proactive effect" interpretation seems more acceptable than one appealing to hypothesis of memory consolidation.

The impairment of a learned avoidance response in rats has been observed to be most effective at relatively short FS-ECS intervals (Quartermain, Paolino, \& Miller, 1965; Chorover \& Schiller, 1965). From the Chorover and Schiller data, with the FS duration of $1 \mathrm{sec}$, it would appear that an FS-ECS interval of 2 sec produces more retrograde amnesia (RA) than either shorter or longer FS-ECS delays. Moreover, Geller, Jarvik, \& Robustelli (1970) have observed a "proactive effect" on testing after one trial FS-ECS. The step-through latency (STL) is much lower at the time of testing than on the original training trial. These authors infer that there is more happening than merely an interference with the consolidation of a memory trace. Such interference would yield a zero training test difference. The "proactive effect" refers to a training test difference opposite in direction to that expected on the basis of FS memory. The present research is aimed at exploring the functional relation between relatively short FS-ECS intervals and test trial STL in mice and determining whether the Chorover and Schiller and the Geller et al data could be partially replicated. Five values of FS-ECS delay were used in order to obtain an RA gradient and to ascertain if a 2-sec delay would yield a maximum RA effect or even a "proactive effect."

\section{SUBJECTS}

The Ss were 70 Swiss-Webster male albino mice, aged 55.65 days. They were housed separately and fed ad lib for 5 days prior to training.

\section{APPARATUS}

The apparatus was a step-through passive avoidance box, $6 \times 3^{1 / 2} \times 5^{1 / 2}$ in., constructed of plywood. The front wall, to which a $1 \times 2 \frac{1}{2}$ in. metal platform was attached, consisted of a $9 \times 18$ in. plywood section. A 1/8-in. brass tube, hinged over a central slot cut into the front wall, carried the small wires to which two miniature toothless alligator clips (the pinnal electrodes) were attached. A 40-W bulb was mounted $91 / 2$ in. above the platform. The interior of the box had a grid floor for FS. A 1-mA FS was delivered from a $1,000-\mathrm{V}$ transformer coupled to an isolation transformer and a 0 - to $135 . \mathrm{V}$ variac. A $1-\mathrm{megohm}$ resistor was in series with the grid. ECS was delivered from the same source in line with a 40,000-ohm resistor. The S's own electrical resistance averaged 30,000 ohms. Mean ECS current was $10 \mathrm{~mA}$. The control circuit is described further in Grosser \& Percy (1971), with one change. $R y_{2}$, the ECS relay, was a $28-\mathrm{V}$ Potter and Brumfield relay with mercury-wetted contacts.

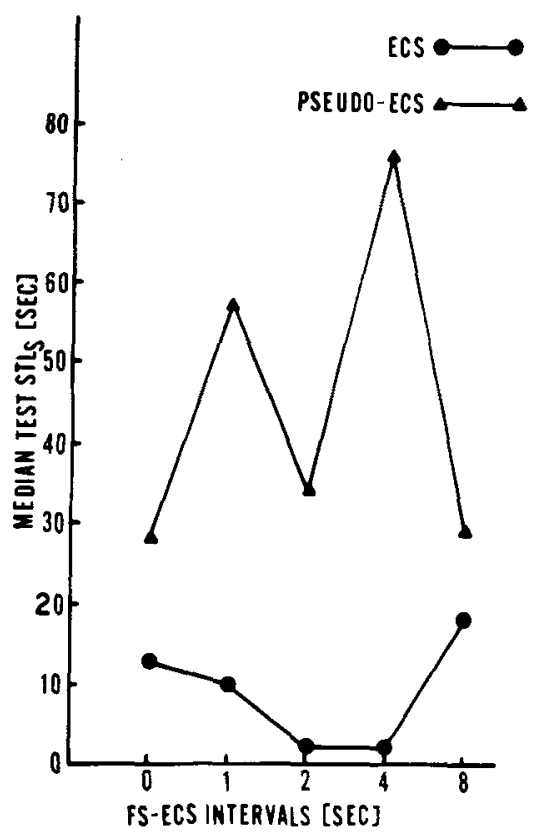

Fig. 1. Median retest STLs for all 10 groups. Note that the experimental function reaches a minimum for Groups E-2 and E-4.

\section{PROCEDURE}

The Ss were randomly assigned to five experimental and five pseudo-ECS control groups. Each experimental group was assigned one of the following FS-ECS intervals: 0, 1, 2, 4, or 8 sec. Each control group was allowed to remain in the apparatus after FS for $0,1,2,4$, or $8 \mathrm{sec}$, respectively. Electrode paste was applied to the ears of all mice and pinnal clips were attached. This was done on the test trial as well as on the learning trial. Each $\mathbf{S}$ was placed on the platform, allowed to make the step-through response, and the STL was recorded. If a $S$ remained on the platform for $3 \mathrm{~min}$, he was removed and the STL was recorded as $180 \mathrm{sec}$ As soon as the $\mathrm{S}$ placed all four feet on the grid, a 1-mA FS of $1-\mathrm{sec}$ duration was delivered. After the appropriate interval, each experimental $S$ received a .2-sec ECS, then was removed from the apparatus. Each control $S$ was removed at the appropriate time following FS. Twenty-four hours after the training trial, the $S$ received a test trial and the STL was recorded.

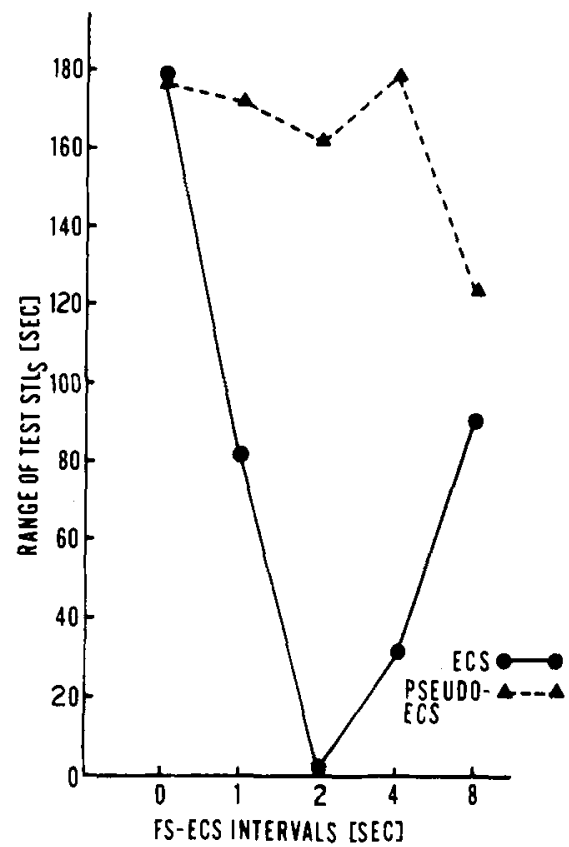

Fig. 2. Range of retest STLs for all 10 groups. Note that the rnage for Group E-2 is extremely low.

\section{RESULTS}

Median STLs for all groups are shown in Fig. 1. The 2-sec and the 4-sec ECS groups comprise a minimum for the function in that, for each group, the median test STL is only 2 sec. The ranges of test STLs for all groups are presented in Fig. 2. The range of $2 \mathrm{sec}$ for all seven Ss of the E-2-sec interval group is much smaller than the range of any other group. 
Table 1

Duncan Range Test of Group Means. All 10 groups (E and C) are analyzed. Data art in common logarithris.

\begin{tabular}{|c|c|c|c|c|c|c|c|c|c|c|c|}
\hline Means & $\begin{array}{c}E-2 \\
.2223\end{array}$ & $\begin{array}{c}E-4 \\
.5797\end{array}$ & $\begin{array}{c}E-1 \\
.8734\end{array}$ & $\begin{array}{c}E-0 \\
1.0307\end{array}$ & $\begin{array}{c}C-0 \\
1.1439\end{array}$ & $\begin{array}{c}E-8 \\
1.1549\end{array}$ & $\begin{array}{c}C-8 \\
1.4156\end{array}$ & $\begin{array}{c}C-4 \\
1.5470\end{array}$ & $\begin{array}{c}C-2 \\
1.6410\end{array}$ & $\begin{array}{c}C-1 \\
1.7399\end{array}$ & $\begin{array}{c}\text { Shortest } \\
\text { Significant } \\
\text { Ranges }\end{array}$ \\
\hline $\mathrm{E}-2=.2223$ & & .3574 & $.6511^{*}$ & $.8084^{*}$ & $.9216^{*}$ & $.9326^{*}$ & $1.1933^{*}$ & $1.3247^{*}$ & $1.4187^{*}$ & $1.5176^{*}$ & $=.5055$ \\
\hline$E-4=.5797$ & & & .2937 & .4510 & $.5642^{*}$ & $.5752^{*}$ & $.8359 *$ & $.9673^{*}$ & $1.0613^{*}$ & $1.1602^{*}$ & $=.5318$ \\
\hline$E-1=.8734$ & & & & .1573 & .2705 & .2815 & .5422 & $.6736 *$ & $.7676^{*}$ & $.8665^{*}$ & $=.5491$ \\
\hline $\mathrm{E}-0=1.0307$ & & & & & .1132 & .1242 & .3849 & .5163 & $.6103^{*}$ & $.7092^{*}$ & $R-5=.5617$ \\
\hline$C-0=1.1439$ & & & & & & .0110 & .2717 & .4031 & .4971 & $.5960^{*}$ & $=.5715$ \\
\hline $\mathrm{E}-8=1.1549$ & & & & & & & .2607 & .3921 & .4861 & $.5850^{*}$ & $R-7=.5792$ \\
\hline$C-8=1.4156$ & & & & & & & & .1314 & .2254 & .3243 & $=.5856$ \\
\hline$C-4=1.5470$ & & & & & & & & & .0940 & .1929 & $R-9=.5910$ \\
\hline $\mathrm{C}-2=1.6410$ & & & & & & & & & & .0989 & $R-10=.5956$ \\
\hline$C-1=1.7399$ & & & & & & & & & & & \\
\hline
\end{tabular}

$* p<.05$

Intermediate range values of 32,81 , and $90 \mathrm{sec}$ are shown by Groups E-4, $E-1$, and $E-8$, respectively. On the other hand, the E-0 group, which received ECS immediately after FS, showed even more individual differences than did any of the control groups, since the range for Group E-0 was $179 \mathrm{sec}$, the highest possible value.

The test trial STL data were subjected to a logarithmic transformation. The resulting transformed scores were tested by the analysis of variance. Groups subjected to ECS after FS were significantly faster than their respective pseudo-ECS controls at stepping into the box on the test trial (F $=41.21$, $\mathrm{df}=1 / 60, \quad \mathrm{p}<.001)$. There was a significant interaction between the ECS variable and the length of the FS-ECS interval $(F=16.39, d f=4 / 60$, $\mathrm{p}<.001$ ).

The Duncan range test was applied to the 10 group means, and this analysis appears in Table 1 . Some of the salient data apparent from this analysis may be noted. The E-2 and E-4 groups show significantly lower log STLs than do the rest of the groups. For the most part, the control groups did not differ among themselves. Group C- 0 , however, had a significantly lower mean log STL than the control group with the longest mean log STL (viz. Group C-1). The experimental groups which differed significantly from their respective controls in having. lower mean log STLs were Groups E-2, E-4, and E-1 (lower than Groups C-2, C-4, and C-1, respectively).

Groups C-0 and E-0 did not differ significantly in mean $\log$ STL. These two groups were highest of all in variability (see Fig. 2); C-O had a range of $178 \mathrm{sec}$ and E-O had a range of $179 \mathrm{sec}$.

In considering the question of whether all the experimental points fall on a straight horizontal line or whether it can be said that the E-2 and E-4 means fall below E-0, E-1, and E-8 means, a reasonable test would be to compare means of successive $E$ groups.
The Duncan test shows that the E-0 vs E-1 mean log STLs do not differ significantly, that the E-2 mean log STL is significantly lower than the E-1 mean $\log$ STL, that the E-2 and E-4 mean log STLs do not differ significantly, and that the E-4 mean log STL is significantly lower than the E-8 mean log STL.

Wilcoxon T tests were performed on training STL vs test STL differences. A single $T$ was performed for the combined control Ss. Significant retention of avoidance was revealed ( $p<.001)$, since test STLs were longer than training STLs.

Experimental Groups E-O and E-1 were combined for a similar analysis. Since training and test latencies were not significantly different, RA for the FS can be said to have occurred.

Experimental Groups E-2 and E-4 were combined for a third $T$ analysis of training vs test STL differences. Here, a significant difference was found $(p<.02)$ in the direction opposite from the one that would indicate retention, i.e., here the test trial STL was shorter than the original STL.

$$
\text { DISCUSSION }
$$

A minimum point of the test trial STL curve is associated with a 2 -sec FS-ECS interval. Furthermore, the E-2 group showed almost no individual variation. This might be interpreted as indicating that the short-term memory trace is most unstable at $2 \mathrm{sec}$ following the acquisition of information. On the other hand, immediate delivery of ECS seemingly produced complete forgetting in four Ss (STL was 1 or $2 \mathrm{sec}$ ) but allowed complete retention (an STL of $180 \mathrm{sec}$ ) in another S. It is not clear why so great a range prevailed for this E-0 group; perhaps two or more conflicting processes are taking place at the moment of acquisition.

The finding of extremely high variability for the experimental and control groups previously removed from the box immediately after footshock (E-0 and C-0) may reflect the possibility that, with such a short time in the box, fear conditioning to cues from the box may have had a chance to occur for only some of the animals. The other animals may have associated the painful footshock with platform cues instead. If the animals could be conditioned equally readily to cues on either one side or the other of the entry hole, this might account for the great variability shown by these two groups.

A further comment is in order regarding Groups E-2 and E-4. These Ss responded more quickly on the test trial than they did on the training trial. This seems to be consistent with the observations of the Geller et al (1970) "proactive effect." The proactive effect indicates that the animals were engaged in something more than passive avoidance learning. Geller et al suggest that this effect may complicate, if not invalidate, the ECS research intended to clarify $R A$.

The reason for performing the FS-ECS experiments has been to subject the hypothesis of memory trace consolidation to close examination with maximum control. The memory trace is established in one learning trial (a painful footshock presentation) and the memory-disrupting factor (ECS) is administered only once. While the methodology seems reasonable, the empirical findings have introduced a basis for doubt in that ECS results in not merely equating test and training trial STLs; it results (at the optimal FS-ECS intervals of 2 and $4 \mathrm{sec}$ ) in a test STL significantly lower than the naive animal's training STL. Perhaps the rapid entry into the box is motivated by fear of footshock, despite the fact that the animal's action puts him in the threatening situation again. Inefficiency in avoiding electric shock is not unknown in mammalian behavior. Monkeys have been known to press a lever apparently in order to obtain painful electric shock to the tail (McKearney, 1969).

REFERENCES

CHOROVER, S. L., \& SCHILLER, P. H. 
Short-term retrograde amnesia in rats. Journal of Comparative \& Physiological Psychology, 1965, 59, 73-78.

GELLER, A., JARVIK, M. E.. \& ROBUSTELLI, F. Permanence of a long temporal gradient of retrograde amnesia induced by electroconvulsive shock.

Psychonomic Science, 1970, 19, 257-259. GROSSER, G. S., \& PERCY, H. E. An apparatus for delivery of electroconvulsive shock without situational change. Journal of the Experimental Analysis of Behavior, 1971. 15, 39-40.

M CKEARNEY, J. W. Fixed-interial schedules of electric shock presentation: Extinction and recovery of performance under different shock intensities and fixed-interval durations. Joumal of the Experimental Analysis of Behavior, 1969 12,301-313.

QUARTERMAIN, D.. PAOLINO, R. M., \& MILLER, N. E. A brief temporal gradient of retrograde amnesia independent of situational change. Science, 1965, 149, $1116-1118$.

\section{CURRENT LITERATURE ON ELECTROCONVULSIVE SHOCK}

BAR RETT, R. J. (Psychology Research Laboratories, Veterans Administration Hospital, Nashville, Tenn. 37203), HUGHES, R. A., \& RAY, O. S. ECS disruption of time-dependent processes in dis criminated-avoidance conditioning in rats: Incubation or consolidation? Journal of Comparative \& Physiological Psychology, 1971, 74, 319-324.

BLACK, M., \& SUBOSKI, M. D. (Queen's University, Kingston, Ontario, Canada). Incubation and ECS-produced gradients in one-trial and multitrial discriminatedavoidance conditioning in rats. Journal of Comparative \& Physiological Psychology, 1971, 74, $325-330$.

DeVIETTI, T. L. (Central Washington State College, Ellensburg, Wash. 98926), \& LARSON, R. C. ECS effects: Evidence supporting state-dependent learning in rats. Journal of Comparative \& Physiological Psychology, 1971, 74, 407-415.

GALLUSCIO, E. H. (554 Gloria Drive, Baton Rouge, La. 70815). Retrograde amnesia induced by electroconvulsive shock and carbon dioxide anesthesia in rats: An attempt to stimulate recovery.
Journal of Comparative \& Physiological Psychology, 1971, 75, 136-140.

GALOSY, R. A. (Behavioral Sciences, Hostos Community College of the City University of New York, 260 East 161 Street, Bronx, N.Y. 10451), \& THOMPSON, R. W. A further investigation of familiarization effects on ECS-produced retrograde amnesia. Psychonomic Science, 1971, 22, 147-148.

GLENDENNING, R. L., \& MEYER, D. R. (202 Kinnear Research Center, Ohio State University, Columbus, Ohio 43212 ). Motivationally related retroactive interference in discrimination learning by rats. Journal of Comparative \& Physiological Psychology, 1971, 75, 153-156.

GR O SSER, G. S. (American International College, Springfield, Mass. 01109), \& PERCY, H. E. An apparatus for delivery of electroconvulsive shock without situational change. Journal of the Experimental Analysis of Behavior, $1971,15,39.40$.

HOWARD, R. L., \& MEYER, D. R. (202 Kinear Research Center, Ohio State University, Columbus, Ohio 43212). Motivational control of retrograde amnesia in rats: $A$ replication and extension. Journal of Comparative \& Physiological Psychology, 1971, 74, 37-40.

MISANIN, J. R. (Susquehanna University, Selinsgrove, $\mathrm{Pa} .17870$ ), SMITH, N. F., \& MILLER, R. R. Memory of electroconvulsive shock as a function of intensity and duration. Psychonomic Science, 1971, 22, 5-7.

OLSON, G. H. (University of New Hampshire, Durham, N.H. 08324), \& HAGSTROM, E. Recovery experiences and the source of aversive effects of electroconvulsive shock. Psychonomic Science, 1971, 22, 161-162.

KESNER, R. P. (University of Utah, Salt Lake City, Utah 84112). ECS as a punishing stimulus: Dependency on retrograde amnesia, duration of anterograde amnesia, and intensity of pain. Journal of Comparative \& Physiological Psychology, 1971, 74, 398-406.

YOUNG, A. G. (Louisiana State University, Baton Rouge, La. 70803), \& GALLUSCIO, E. H. Recovery from ECS-produced amnesia. Psychonomic Science, 1971, 22, 149-151. 